Running head: EMERGING ADULTS' "IN BETWEEN" RELATIONSHIPS

\title{
WHAT ARE WE? THE NATURE OF AND MOTIVATIONS BEHIND EMERGING ADULTS' “IN BETWEEN” RELATIONSHIPS
}

James Montilla Doble and Reiniero S. Gutierrez

A Thesis Submitted to the Social Science Division Kalayaan College New Manila, Quezon City

In Partial Fulfillment of the Requirements For the Degree of Bachelor of Arts in Psychology

May 2017 


\section{TABLE OF CONTENTS}

CURRICULUM VITAE

$\begin{array}{ll}\text { ABSTRACT } & 1\end{array}$

CHAPTER ONE: Introduction 2

Research Objectives $\quad 3$

Significance of the Study $\quad 4$

Scope and Limitations of the Study 4

CHAPTER TWO: Review of Related Literature $\quad 6$

$\begin{array}{ll}\text { Theories on Relationship Development } & 6\end{array}$

Romantic Relationship Transitions and Trajectories 11

$\begin{array}{ll}\text { Relational Uncertainty } & 16\end{array}$

Romantic Relationships in Emerging Adulthood 20

CHAPTER THREE: Methods 22

$\begin{array}{ll}\text { Research Design } & 22\end{array}$

$\begin{array}{ll}\text { Participants } & 22\end{array}$

$\begin{array}{ll}\text { Measures } & 22\end{array}$

$\begin{array}{ll}\text { Procedure } & 23\end{array}$

CHAPTER FOUR: Data, Results and Discussion 24

$\begin{array}{ll}\text { Participants' Demographics } & 24\end{array}$

Discussion of Themes and Sub-themes $\quad 24$

General Discussion $\quad 32$

$\begin{array}{ll}\text { Conceptual Framework } & 36\end{array}$

CHAPTER FIVE: Summary, Conclusion, and Recommendations 40 
EMERGING ADULTS' “IN BETWEEN” RELATIONSHIPS

$\begin{array}{ll}\text { Summary } & 40\end{array}$

$\begin{array}{ll}\text { Conclusion } & 41\end{array}$

$\begin{array}{ll}\text { Recommendations } & 41\end{array}$

$\begin{array}{lr}\text { BIBLIOGRAPHY } & 43\end{array}$

$\begin{array}{lr}\text { APPENDICES } & 48\end{array}$

Appendix A: Informed Consent Form 48

Appendix B: Semi-Structured Interview Questions $\quad 50$ 


\section{ABSTRACT}

"In between" relationships (IBRs) constitute experiences and relationships that, when described, overlap between friendships and romantic relationships. They are, therefore, characterized by definitional uncertainty, as well as the other types of relational uncertainty identified by Knobloch and Solomon (1999). In this study, semi-structured interviews were conducted among emerging adults with ongoing and terminated IBRs to provide information regarding the nature of these relationships and motivations behind them. Topic avoidance reinforces the prevalent relational uncertainty among IBRs. IBRs also have advantages, such as companionship, sex, and positive feelings, as well as some disadvantages, such as stress, lack of exclusivity, and negative feelings. These advantages motivated emerging adults to initiate and maintain their IBRs, but the disadvantages that followed can become a contributing factor to its termination. In addition, emerging adults perceive IBRs to be "safer" than being in a committed romantic relationship, which motivates IBR maintenance even more. 


\section{CHAPTER ONE}

\section{Introduction}

“Are we in a relationship? Or aren't we?"

Ambiguity is on the rise among emerging adults' relationships. Relationship stages used to be clearly delineated, yet have become less structured over the years (Stanley, 2002 June). USA Today published an article accompanied by the results of online survey in 2014, discussing how people are confused whether or not "hanging out" with someone they are interested in is a “date.” Both Vox's thinkpiece, How Dates Got So Complicated as well as Chicago Tribune's Forever? Maybe. But Not Just Yet. talk about the cultural, technological, and other generational changes that may have contributed to why emerging adults' face vague norms in the romantic relationship realm. These social developments - increasing women's agency over time, placing less value on marriage and marrying early (Carroll et al., 2007), and increasing liberalism towards premarital sex (Halpern, Waller, Spriggs, \& Hallfors, 2006) among others-combined with the instability characterizing this period of development can be one of the reasons relationships among emerging adults are diverse as well as oscillating (Arnett, 2004).

Among these various relationships are casual sexual relationships_-among which are “one-night stands" and "friends with benefits" (Wentland \& Reissing, 2014) — and "in between" relationships, i.e., experiences and relationships that overlap between friendships and romantic relationships and, therefore, are characterized by definitional uncertainty as well as other forms of relational uncertainty (as identified by Knobloch and Solomon (1999)). These are relatively new phenomena, yet unlike casual sexual relationships that have been studied in depth (e.g., Regan \& Dreyer, 1999; Grello, Welsh, \& Harper, 2006; Claxton \& van Dulmen, 2013; Wentland \& Reissing, 2014), “in between" relationships have not been as fortunate. 
"In between" relationships are not unheard of among millennials — individuals born in the early 1980s until the year 2000, with most of them now currently emerging adults (18-29 years old). A quick internet search on "ambiguous relationships," "relationships with no labels," or "vague relationships," reveals countless blog articles on how to cope with them, as well as how to DTR (or "define the relationship," according to Urban Dictionary). Because this phenomenon is relatively understudied, this study serves as an initial exploration of the nature of as well as the motivations behind "in between" relationships.

\section{Research Objectives}

This research sought to provide insight on the nature of the phenomenon of "in between" relationships among emerging adults, and aimed to do the following as well:

- Study the nature of the phenomenon of "in between" relationships among emerging adults, specifically in terms of relationship development

- Learn how "in between" relationships are initiated, maintained, and terminated

- Determine what cognitive, affective, and behavioral responses occur in an "in between" relationship

- Learn how "in between" relationships are similar to and different from friendships and romantic relationships

- Identify the motivations behind "in between" relationships as well as how long emerging adults engage in them

- Provide likely explanations as to why emerging adults to engage in "in between" relationships

- Conceptualize a framework that illustrates the development of "in between" relationships, expanding the existing literature on relationship development 


\section{Significance of the Study}

This study and its subsequent findings will be numerously helpful: Knowing the nature of "in between" relationships (specifically, how this transitional type of relationship is initiated, maintained, and terminated) as well as the motivations behind them will aid in explaining why people are in, or would choose to be in, "in between" relationships. This research also compared "in between" relationships to friendships and romantic relationships, as well as contrasted them.

Emerging adults face confusion in vague relational arrangements. The researchers believe that the transitional relationship between friendships and romantic relationships, or an "in between" relationship, is an important stage of relationship development among modern emerging adults. This study hopes to give clarity in the ambiguous nature of this phenomenon. Individuals who are engaging in, have engaged in, or desire/have plans to engage in, "in between" relationships will now have an idea on what sort of emotional and behavioral responses and thought processes happen in these relationships, and what "in between" relationships would entail. This research, in addition, may guide emerging adults into which responses are in accordance with the nature of their "in between" relationship.

This study also helped the researchers conceptualize a framework that illustrates the development of "in between" relationships as an attempt to expand the existing literature on relationship development.

\section{Scope and Limitations of the Study}

This study was limited to emerging adults who, at the time this study was conducted, were in an "in between" relationship or had been in one. Their age for the majority of duration of the relationship was 18-29 years. They were also residents of Metro Manila. 
The researchers recognized participants' different viewpoints towards relationships in general, but they hoped to identify common factors that could influence their being in or choosing to be specifically in "in between" relationships. 


\section{CHAPTER TWO}

\section{Review of Related Literature}

\section{Theories on Relationship Development}

Several theories aim to describe and explain the processes by which relationships develop. Some are linear in that they depict relationship development in a sequential manner, moving through varying stages as is typical (e.g., social penetration theory, relational stages model). However, some are non-linear, illustrating relationship development more openly, therefore allowing for more flexibility and accounting for both conventional and unconventional relationships (e.g., turning point approach, uncertainty reduction theory, expectancy violations theory).

Altman and Taylor's (1973) social penetration theory. Communication within relationships develops from superficial and non-intimate to highly personal and therefore, more intimate. This happens because of self-disclosure, which, according to Altman and Taylor (1973), is akin to peeling the layers of an onion. As individuals disclose information about themselves, they penetrate through their facades and peel back their figurative layers, slowly unveiling their true personalities as they reach the core.

Social penetration refers to reciprocal behaviors that occur between people during relationship development, which comprise of exchange of information, exchange of expressions of positive and negative affect, and shared activities (Taylor, 1968). This development proceeds along two dimensions: breadth and depth of penetration. The former is the amount of interaction (information, affect, activities) per a specific unit of time, whereas the latter is the degree of intimacy characterizing a typical interaction. 
The stages of self-disclosure-orientation, exploratory affective, affective, and stabledepict how this penetration moves from small talk to meaningful and emotionally deep conversations (Altman and Taylor, 1973). This "forward" movement happens because rewards and costs have been evaluated positively. Vulnerability and increased intimacy are results of selfdisclosure, and individuals may self-disclose even more if increased intimacy outweighs any emotional risks. However, depenetration ("backward" movement) may occur when rewards and costs have been evaluated negatively in that self-disclosure - and therefore, becoming intimate and emotionally vulnerable — is thought of as jeopardizing behavior.

Knapp's (1984) relational stages model. Knapp's model has 10 stages, five of which illustrate "coming together" (relationship development) and the other five depict "coming apart" (relationship dissolution). The five stages of relationship development are initiating, experimenting, intensifying, integrating, and bonding. The five stages of relationship dissolution are differentiating, circumscribing, stagnating, avoiding, and terminating.

The relational stages model is often conceptualized through a dual staircase wherein relationships can go up and down, and even move sideways. Movement through the model is determined by social exchange theory as well as social penetration theory (Avtgis, West, \& Anderson, 1998). In other words, evaluating a relationship's rewards and costs influence and lead to decisions about the relationship's direction (where it will go) and its motivational power (how fast it will get there).

Baxter and Bullis' (1986) turning point approach. Linear stage theories, such as Altman and Taylor's (1973) social penetration theory and Knapp's (1984) relational stages model, differ from Baxter and Bullis' turning point approach, which states that relationships progress nonlinearly. Turning points are events connected to changes in the relationship (Baxter 
$\&$ Bullis, 1986). They are also associated with shifts in commitment as well as in relational satisfaction. Turning points, when mapped out, show patterns of highs and lows instead of gradual changes in intimacy, supporting some studies' suggestion that linear trajectories of relationship development explains only 40 to $50 \%$ of friendships (Johnson et al., 2003; Johnson, Wittenberg, Villagran, Mazur, \& Villagran, 2004).

Turning points that increase intimacy and are common in friendships include quality time and sacrifice (Johnson et al., 2003, 2004). In romantic relationships, they consist of get-to-know time, physical separation and reunion, passion, disengagement and making up, etc. (Baxter \& Bullis, 1986). Some of them-external competition, exclusivity, and serious commitment-are turning points that distinguish the latter from the former. On a larger scale, they may even indicate the transition from friendship to romantic relationship (Guerrero \& Mongeau, 2008).

Romantic relationship transitions are macrolevel turning points that signal a length of time wherein a relationship begins to shift from platonic or nonexistent to romantic (Mongeau et. al, 2006). They happen at least once during transition, regardless of the preexisting relationship between individuals; they can include first-time events in a relationship, but are not limited to these turning points (Guerrero \& Mongeau, 2008; Mongeau et. al, 2006).

Berger and Calabrese's (1975) uncertainty reduction theory. Understanding is the goal of social interaction (Berger \& Calabrese, 1975). When people are uncertain, therefore lacking understanding within their relationships, they seek out information that will reduce uncertainty. This drives individuals to do so because uncertainty reflects a lack of sureness, or the inability to estimate how an interpersonal encounter will advance and to explain behavior during social interactions (Berger \& Calabrese, 1975; Knobloch \& Solomon, 1999). 
There are three different sources of uncertainty: the self, the partner, and the relationship. Self uncertainty happens when people are unable to describe, predict, or explain their own attitudes or behavior, which results from not knowing one's self fully (Berger \& Bradac, 1982; Berger \& Calabrese, 1975). Partner uncertainty occurs when information about the partner's likes, dislikes, moral standards and principles, tendencies, etc. is inadequate (Berger, 1979). Therefore, individuals are unable to predict their partner's attitudes or behavior (Berger \& Bradac, 1982; Berger \& Calabrese, 1975). Relationship uncertainty happens when people doubt the relationship's status, which has been hypothesized to be harder to reduce because it goes beyond self and partner uncertainty and focuses on the dyad as one unit (Berger \& Bradac, 1982).

There are two kinds of content of uncertainty in interpersonal interactions: behavioral and cognitive (Berger, 1979). The former involves not knowing how to act during these encounters, whereas the latter involves not knowing particular content or information. There are, however, three content issues for self and partner uncertainty and four content issues for relationship uncertainty (Knobloch \& Solomon, 1999). Self and partner uncertainty comprises issues on desire for the relationship, evaluation of the relationship, and goals for the relationship. These refer to whether one aspires to pursue the relationship or not (desire), based on how beneficial the relationship is or could become (evaluation), as well as what one wants from the relationship and how committed they are to it (goals). Relationship uncertainty includes behavioral norms uncertainty (uncertainty about how one should behave in the relationship), mutuality uncertainty (uncertainty as to whether feelings are reciprocated or not), definition uncertainty (uncertainty about the relationship's state or nature), and future uncertainty (uncertainty referring to commitment and where the relationship could lead). 
According to uncertainty reduction theory, interpersonal relationships develop as uncertainty within the relationship lessens (Berger \& Calabrese, 1975). In spite of this, people in close relationships may also experience uncertainty at different points in their relationship, with some sources and content of uncertainty becoming more pertinent depending on the nature of the relationship (Guerrero \& Mongeau, 2008).

Burgoon's (1978) expectancy violations theory. People attach certain expectations to friends and romantic partners with regards to how they should act (Guerrero \& Mongeau, 2008). Throughout a relationship's course, these expectations are subject to change, such as when a relationship shifts in definition. Naturally, this is the case when friendships evolve into romantic relationships.

Expectations are lasting societal perceptions regarding the behavior anticipated of individuals (Burgoon, 2015). These expectations derive from information about the communicator (other person), the context (situation), as well as the pre-existing relationship between an individual and the other person. Societal norms influence these expectations as well.

An important concept of expectancy violations theory is communicator reward valence or reward value. The target (recipient of the violation) evaluates the communicator (person doing the violation) based on dimensions such as attractiveness, status, intelligence, etc. The target then takes all these separate evaluations and combines them, placing the communicator along the reward valence continuum which ranges from extremely positive to extremely negative. This interpretation plays a role in whether expectations are met (expectancy confirmations) or unmet. Expectancy violations are unmet expectations. The target assesses the desirability of these violations based on where the communicator lies on the reward valence continuum. If the communicator's reward value is positive, expectancy violations would be 
evaluated as desirable (positive violations), whereas they would be undesirable (negative violations) if the communicator's reward value is negative.

Relevant to the transition from friends to romantic partners are four kinds of expectancy violations: relationship escalation (i.e., behaviors that deepen commitment; e.g., saying "I love you"), uncharacteristic relational behavior (i.e., behaviors inconsistent with the definition of the relationship; e.g., wanting to go on a date with your friend), acts of devotion (i.e., behaviors that show that someone is important or special; e.g., doing favors), and gestures of inclusion (i.e., behaviors that include or show one's desire to include someone into one's social circle; e.g., wanting your friend to celebrate the holidays with you) (Afifi \& Metts, 1998; Guerrero \& Mongeau, 2008).

In short, expectancy violations are not positive or negative on their own. Their valence lies on how they are interpreted and made sense of by the target (Burgoon, 2015). Positive assessments of expectancy violations can predict whether a friendship transitions into a romantic relationship. Negative evaluations, however, could mean that these transitions are not as likely to happen (Guerrero \& Mongeau, 2008).

\section{Romantic Relationship Transitions and Trajectories}

An "in between" relationship could occur in the midst of no less than three trajectories. It could happen between acquaintances, friends, and "friends with benefits" — all of which could transition into romantic partners. This part shall discuss these kinds of trajectories as well as the romantic relationship transitions that can occur while a relationship undergoes growth or significant change. 
Romantic relationship transitions. Romantic relationship transitions are larger-scale turning points in relationships. Specifically, this refers to a moment in time when a relationship changes "from being platonic or nonexistent to being romantic" (Mongeau et al., 2006).

Turning points within romantic relationship transitions can include, among others: a first date, a first kiss, a first sexual activity or intercourse, or a first-time disclosure of feelings (Guerrero \& Mongeau, 2008). Romantic relationship transitions are complex processes that happen at least once during transition, regardless of the preexisting relationship between individuals: acquaintances, friends, or "friends with benefits." They involve changes in affect, behavior, and cognition that characterize smaller turning points, all of which occur during relationship development or when a relationship is transitioning (Mongeau et al., 2006).

Acquaintances to romantic partners. Theories such as Altman and Taylor's (1973) social penetration theory and Knapp's (1984) relational stages model illustrate a linear development from being acquaintances to being romantic partners. According to Altman and Taylor's social penetration theory, this "traditional" trajectory involves increasing intimacy through self-disclosure. Its four stages (orientation, exploratory affective exchange, affective exchange, and stable exchange) depict this gradually, with small talk eventually evolving into more personal self-disclosure as individuals get to know and become comfortable with one another.

Knapp's relational stages model, however, is composed of five stages of relationship development: initiating, experimenting, intensifying, integrating, and bonding. It is in the experimenting stage that discovering the unknown about the other occurs. During the intensifying stage, however, people become close and intimate friends. They go through 
coupling in the integrating stage, taking their relationship to the next level (Knapp \& Vangelisti, 2005).

Avtgis et. al (1998) extended Knapp's relational stages model by identifying the model's cognitive, affective, and behavioral dimensions, therefore concretizing what occurs during these stages. The experimenting stage involves talking about past relationships, family, and hobbies, and trying to make a good impression. Feelings of comfort and connectedness as well as feelings of uncertainty are perceivably common in this stage. Activities that people do include calling or visiting each other, eating meals and going on dates, touching each other, and impressing their partner. Individuals whose relationships are characteristically in the intensifying stage inquire about moral values. They feel happy and loving, as well as warm and close to and wanted and needed by their partner. People in this stage hold hands, hug, and kiss. They also make plans together, buy gifts and do spontaneous favors for their partner, and even make mental predictions about their future together. Coalescing of individual personalities happens during the integrating stage (Knapp \& Vangelisti, 2005). This results in feelings of unity and oneness, and unhappiness when separation occurs (Avtgis et. al, 1998). Partners talk about their future together, reflect about their mutual experiences or things done together, and share deep feelings. Their social circles unite, and they go on vacation together and meet each other's families and friends.

Friends to romantic partners. Stages theories are limiting with regards in their ability to explain this second kind of trajectory. This is because various types of intimacy and attraction develop simultaneously in these theories, discounting the fact that they take different forms in different social interactions (Guerrero \& Mongeau, 2008).

According to Robert Sternberg's (1968) triangular theory of love, love has three main components: intimacy, passion, and decision/commitment. These components, when combined 
one way or another, create eight different forms of love, two of which are liking or platonic love (composed of intimacy only, no passion and decision/commitment) and romance or romantic love (composed of intimacy and passion only, no decision/commitment). Intimacy in both forms differ - the former being more of the friendship-based kind, and the latter passion-based. Friendship-based intimacy comes from an emotional connection or investment between individuals, as well as understanding and warmth. Passion-based intimacy, however, is due to romantic and sexual feelings (Guerrero \& Mongeau, 2008).

Liking and romance also differ in terms of attraction. Romance involves the arousal that comes with physical-sexual attraction - the first type of attraction identified by Reeder (2000) whereas liking does not. However, it does include the second type of attraction, which is friendship attraction. The third type is romantic attraction, or the desire to form a romantic relationship or to be romantic partners with someone or, more specifically, with a friend. Both friendship-based intimacy as well as friendship attraction characterize and ground many friendships that eventually develop into romantic relationships.

Unlike the linear trajectory wherein different forms of intimacy and attraction are assumed to develop at the same rate, the usual trajectory from friends to romantic partners involves adding passion-based intimacy as well as physical-sexual and romantic attraction into a pre-existing friendship in order for it to develop into a romantic relationship.

"Friends with benefits" to romantic partners. "Friends with benefits" relationships incorporate the "benefits" of a casual sexual relationship (e.g., sex without commitment, responsibilities, or "strings" attached to it) into an existing friendship (Wentland \& Reissing, 2014). In doing so, the design of "friends with benefits" relationships is not to advance their "friends with benefits" relationship into a romantic relationship, nor to increase one's 
commitment to their partner as well as to their relationship. Considering the very nature of these relationships, expectations and wants within "friends with benefits" relationships still differ individually. People would have concealed desires towards a committed, exclusive relationship with their partner (Williams \& Adams, 2013). Some have even actively engaged in "friends with benefits" relationships in order to escalate their friendship into a romantic relationship, such as the "successful transition in" type of "friends with benefits" relationships, whereas others have inadvertently advanced their friendship, such as the "unintentional transition" type (Mongeau et al., 2013).

Many "friends with benefits" relationships — approximately 90\%—fail to develop into romantic relationships (Bisson \& Levine, 2009). For those that do, however-specifically partners who start off as the "true friends" type, i.e., close friends before the "friends with benefits" relationship (Mongeau et al., 2013) — they challenge prototypical ideas of how romantic relationships evolve and what it actually means to be "friends" compared to a "romantic couple" (Guerrero \& Mongeau, 2008). They highly differ from romantic relationships wherein the partners were initially acquaintances or friends, because friendship-based intimacy and passion-based intimacy have already developed in "friends with benefits" relationships. These different forms of intimacy could precede romantic attraction too, but not friendship attraction and physical-sexual attraction, which could occur simultaneously with friendshipbased intimacy and passion-based intimacy amidst these relationships.

The complex trajectory from "friends with benefits" to romantic partners often no longer deals with adding or increasing intimacy and attraction, but with negotiating terms of transitioning into a romantic relationship amidst changing expectations. 


\section{Relational Uncertainty}

Romantic potential relationships (friendships that have romantic potential), such as "in between" relationships, are more vague than either friendships or romantic relationships (Baxter $\&$ Wilmot, 1985). Because there is a lack of consensus on what the relationship is, relationships in transition are more often than not characterized by uncertainty. Relational uncertainty has been conceptualized as "the degree of confidence people have in their perceptions of involvement” within their relationships (Knobloch \& Solomon, 1999).

Relational uncertainty in transitional relationships. People in close and established relationships, such as friendships and romantic relationships, may experience uncertainty (Guerrero \& Mongeau, 2008). Certain events can lead to uncertainty, such as competing relationships (e.g., your friend starts dating someone else) unexplained loss of closeness or contact (e.g., your friend stops sending you messages for no particular reason), sexual behavior (e.g., your friend discloses information about their sexual history), deception (e.g., your friend is caught keeping secrets or lying), change in personality or values (e.g., your friend starts becoming flirtatious with or affectionate towards you), and betraying confidence (e.g., your friend tells third parties information about you) (Planalp \& Honeycutt, 1985).

In relationships in transition, some events are more relevant than others (Guerrero \& Mongeau, 2008). Competing relationships could lead to emotions such as jealousy, which may trigger a realization that someone likes their friend, whereas changes in personality could signal that someone's friend is interested in them romantically.

People in transitional relationships, such as "in between" relationships, could also experience at least one of the four types of relational uncertainty, be it uncertainty in terms of how one should behave in the relationship (behavioral norm uncertainty), whether feelings are 
reciprocated or not (mutuality uncertainty), the relationship's state or nature (definition uncertainty), or commitment and where the relationship could lead (future uncertainty) (Knobloch \& Solomon, 1999). Research suggests that these relationships are more likely to be characterized by uncertainty than relationships in its initial stages. The relational turbulence model builds on this implication, stating that uncertainty is most likely when a relationship transitions from casual into a more committed one, and it peaks during the middle stages of a relationship (Solomon \& Knobloch, 2001). This is assumed to be the result of having to renegotiate interdependence levels and to adjust expectancies within the relationship. Transitional relationships, in addition to what has already been mentioned earlier, also have to renegotiate commitment levels as well as the state of the relationship, therefore allowing the relational turbulence model to explain them as well (Guerrero \& Mongeau, 2008).

Topic avoidance. Self-disclosure, according to social penetration theory (Altman \& Taylor, 1973), plays an important role during relationship development, particularly in the intensifying stage of Knapp's (1984) relational stages model. Topic avoidance (wherein a person intentionally does not disclose information on a particular subject), however, can occur among both friends and dating partners.

Relationship issues (e.g., talking about the state of the relationship or disclosing feelings), negative experiences and failures, romantic relationship experiences (e.g., relationship history, former dating or marital partners), sexual experiences (e.g., sexual history or preferences), and outside friendships (e.g., activities shared with other friends, feelings for other friends) are taboo topics common in friendships and dating relationships (Afifi \& Guerrero, 1998). The "state of the relationship" is a common off-limits topic in friendships (Baxter \& Wilmot, 1984). Friends avoid talking about these taboo topics, particularly about relationship issues, more than dating 
partners do (Afifi \& Burgoon, 1998). They do so in order to protect their friendship (Messman et al., 2000), and since there is likely to be uncertainty regarding their friend's desires or true feelings (Guerrero \& Mongeau, 2008). Notwithstanding the relationship type, wanting to keep the relationship is the strongest predictor of topic avoidance (Afifi \& Guerrero, 1998; Baxter \& Wilmot, 1985).

Uncertainty is linked to topic avoidance in friendships. People in friendships characterized by high levels of uncertainty were found to participate in less relationship talk (Afifi \& Burgoon, 1998). The direction of this link is unclear, however. It could be due to uncertainty about how their friend may react or the possibility that revealing their feelings could impact the friendship negatively. On the other hand, uncertainty could also be because of the significantly less amount of relationship talk (Guerrero \& Mongeau, 2008).

There is a lack of research on changes in topic avoidance in transitional relationships (Guerrero \& Mongeau, 2008). Knoblock and Carpenter-Theune (2004), however, learned that at moderate levels of intimacy or when dating partners go from casual dating to serious, topic avoidance is at its most frequent. They tread lightly around sensitive topics, particularly ones that may disrupt or, at worst, damage the relationship. In the case of friendships transitioning into romantic relationships, friends who think that their feelings could be unreciprocated may avoid talking about the state of the relationship. The most topic avoidance may illustrate relationships in transition, especially at instances when mutuality uncertainty occurs in these arrangements (Guerrero \& Mongeau, 2008).

Secret tests. Uncertainty on relationship issues, such as the nature or the state of the relationship, can be reduced by seeking information either passively (i.e., through unobtrusively observing a target), actively (i.e., through indirectly "testing" a target, or asking third-party 
individuals), or interactively (i.e., through directly engaging with a target) (Berger \& Bradac, 1982). In 1985, Baxter and Wilmot enumerated six types of information-seeking techniques or secret tests. These included third-party tests (i.e., asking mutual friends if your friend is interested in you), public-presentation tests (i.e., introducing your friend as your boyfriend or girlfriend to see their reaction), indirect-suggestion tests (i.e., joking or hinting to your friend about being a couple to see their reaction), endurance tests (i.e., decreasing "rewards" or increasing "costs" to see if your friend will still want to be your friend), separation tests (i.e., deliberately distancing from your friend to see if they will miss you), and triangle tests (i.e., flirting with someone else to see your friend's reaction) — all of which reduce uncertainty in relationships.

These techniques, when used right, can be a means to get information without having to resort to self-disclosure or direct questioning. People in romantic potential relationships use secret tests more than people in strictly platonic friendships and romantic relationships. Indirectsuggestion tests and separation tests are the most utilized among the six types, whereas thirdparty tests and public presentation tests are the least used (Baxter \& Wilmot, 1985). Directness tests (ones involving self-disclosure or direct questioning) were seldom used by people in romantic potential relationships, showing a preference for indirect information-seeking strategies rather than direct ones when in a transitional relationship. This could be due to perceived risks involved during self-disclosure as well as the desire to safeguard the friendship from unnecessary harm. Including third parties, despite the indirect approach, may also jeopardize the relationship because it confirms the presence of an individual's romantic feelings or desires for their friend. 


\section{Romantic Relationships in Emerging Adulthood \\ Definition of emerging adulthood. Coined by Arnett (2000), emerging adulthood refers} to a developmental period from the late teens extending to the twenties. It is neither adolescence nor young adulthood, because emerging adulthood is distinct theoretically and empirically, with emerging adults seeing themselves as no longer adolescents, yet at the same time, not quite adults. Postponing transitions and significant life events, such as marriage and parenting, allows people from urban or industrialized societies that fall under the ages 18 to 29 to explore and engage in many different possible life directions (Arnett, 2014).

\section{Characteristics of romantic relationships in emerging adulthood. Exploration and} change are themes common and central to emerging adulthood (Arnett, 2000). The semiautonomous and unstable nature of this period makes it an ideal time to have varying romantic and sexual experiences.

During adolescence, dating is "primarily recreational" (Roscoe, Diane, \& Brooks, 1987). Romantic relationships in emerging adulthood, however, occur between couples (Arnett, 2000). They are more intimate and serious as they are less transient and last significantly longer than adolescent relationships. There is an emphasis on emotional and physical intimacy, so it is no surprise that romantic relationships in emerging adulthood may also include sexual intercourse as well as cohabitation (Michael, Gagnon, Laumann, \& Kolata, 1995).

There is a recurring stereotype that emerging adulthood relationships are very sexual, characterized with uncertainty and lacking in stability (e.g., Claxton \& van Dulmen, 2013; Halpern-Meekin, Manning, Giordano, Longmore, 2012; Stanley, Rhoades, \& Fincham, 2011). However, a study by Roberson, Norona, Fish, Olmstead, and Fincham (2016) reveals that romantic relationships in emerging adulthood vary, with some contradicting the dominant 
perception of how emerging adults engage in them. This occurred despite the inherent instability prevalent during this time period, and these atypical relationships even comprised the majority of the aforementioned study. 


\section{CHAPTER THREE}

\section{Methods}

\section{Research Design}

The researchers utilized a qualitative research design. Because this study aimed to lay the groundwork on the development of "in between" relationships and to capture their nature as well as the motivations behind these relationships, a qualitative research design assured the data's depth, despite the limited number of participants. The data was gathered through semi-structured interviews, and studied in terms of the participants' respective narratives (narrative analysis) and through thematic analysis.

\section{Participants}

The participants for this study were Metro Manila-based emerging adults, ages 18 to 29, who were currently in an "in between" relationship or had been in one not longer than three years from the time this study was conducted.

The researchers used both purposive sampling and snowball sampling methods, since the participants had to be in or had been in an "in between" relationship and of a specific age group and they may know other people who are in or were in a similar arrangement. They identified the participants by asking: "Have you ever been in a relationship 'na parang kayo, pero hindi?' (... wherein it seems you are together, but you are not?)"

\section{Measures}

The researchers utilized both narrative analysis and thematic analysis in this study. Narrative analysis was done through semi-structured interviews. The semi-structured interview was composed of nine questions about the participants" "in between" relationships, with three 
questions having several follow-up questions. Thematic analysis was done through affinity diagrams or $\mathrm{KJ}$ method.

\section{Procedure}

The researchers conducted five face-to-face interviews. They used narrative analysis and thematic analysis to study the data from these, identifying preliminary themes and sub-themes. The researchers revised the interview questions, if necessary, before they conducted 16 more interviews and subsequently analyzed them using the aforementioned measures.

After identifying final themes and sub-themes from the data, the researchers conceptualized a framework that illustrates the development of "in between" relationships. 


\section{CHAPTER FOUR}

\section{Data, Results, and Discussion}

\section{Participants' Demographics}

The interview participants $(n=21)$ consisted of 11 females and 10 males, whose mean age is 22.33 years. The average length of their "in between" relationships is 11.29 months. Seventeen of the participants' "in between" relationships were cross-sex, whereas four were same-sex.

\begin{tabular}{|l|l|}
\hline Table 1. Participants' demographics & \\
\hline $\begin{array}{l}\text { Sex } \\
\text { Female }\end{array}$ & $\begin{array}{l}11(52.38 \%) \\
10(47.62 \%)\end{array}$ \\
\hline Age & $\begin{array}{l}\bar{x}=22.33 \\
\text { (range: } 19-27)\end{array}$ \\
\hline Length of IBR (months) & $\begin{array}{l}\overline{\mathrm{x}}=11.29 \\
\text { (range: } 2-44)\end{array}$ \\
\hline $\begin{array}{l}\text { Relationship type } \\
\text { Cross-sex } \\
\text { Same-sex }\end{array}$ & $\begin{array}{l}17(80.95 \%) \\
4(19.05 \%)\end{array}$ \\
\hline
\end{tabular}

\section{Discussion of Themes and Sub-themes}

The researchers' analysis of the data yielded seven themes and 20 sub-themes that are summarized in Table 2 and explained in detail below.

Theme 1: "In between" relationships are intimate. "In between" relationships are characteristically between friendships and romantic relationships, both of which come with different forms of intimacy. Friendship-based intimacy prevails amongst friends, whereas romantic partners who started off as friends, would have passion-based intimacy alongside the former. "In between" relationships, therefore, are also intimate. 


\begin{tabular}{|c|c|}
\hline Themes & Sub-themes \\
\hline $\begin{array}{l}\text { Theme 1: "In between" relationships (IBRs) are } \\
\text { intimate }\end{array}$ & $\begin{array}{l}\text { - Increased amounts of self-disclosure lead to increased } \\
\text { intimacy } \\
\text { - Other interactions, such as shared activities, can also } \\
\text { lead to increased intimacy }\end{array}$ \\
\hline $\begin{array}{l}\text { Theme 2: Expectancy changes and violations as well as } \\
\text { turning points can occur within IBRs }\end{array}$ & $\begin{array}{l}\text { - People's expectancies can change and be violated } \\
\text { within the relationship } \\
\text { - Turning points, which signal change, can occur as } \\
\text { well }\end{array}$ \\
\hline $\begin{array}{l}\text { Theme 3: IBRs are characterized by relational } \\
\text { uncertainty }\end{array}$ & $\begin{array}{l}\text { - People, regardless what their initial relationship is, } \\
\text { start to become unsure of the state of the relationship } \\
\text { - They also become unsure of how to behave within the } \\
\text { relationship, of whether their feelings are reciprocated } \\
\text { or not, of their or their partner's commitment to the } \\
\text { relationship and where the relationship could lead } \\
\text { - Reducing this uncertainty could lead to either the } \\
\text { IBR's development into a romantic relationship or to } \\
\text { its termination }\end{array}$ \\
\hline $\begin{array}{l}\text { Theme 4: Topic avoidance occurs within and maintains } \\
\text { IBRs }\end{array}$ & $\begin{array}{l}\text { - People in IBRs avoid talking about the state of the } \\
\text { relationship } \\
\text { - Talking about the state of the relationship could lead } \\
\text { to its termination } \\
\text { - People would rather choose to "play it safe" than } \\
\text { "rock the boat" }\end{array}$ \\
\hline $\begin{array}{l}\text { Theme 5: Cognitions, affect, and behavior (CABs) } \\
\text { associated with IBRs include CABs associated with } \\
\text { both friendships and romantic relationships }\end{array}$ & $\begin{array}{l}\text { - People in IBRs think, feel, and do things that they } \\
\text { associate with friendships } \\
\text { - They also think, feel, and do things that they associate } \\
\text { with romantic relationships }\end{array}$ \\
\hline Theme 6: IBRs have advantages & $\begin{array}{l}\text { - IBRs elicit positive affect (excitement, fun, intimacy) } \\
\text { - IBRs provide people with companionship and sex } \\
\text { without the commitment associated with a romantic } \\
\text { relationship } \\
\text { - IBRs also provide perceived safety } \\
\text { - In retrospect, IBRs can become a learning experience }\end{array}$ \\
\hline Theme 7: IBRs have disadvantages & $\begin{array}{l}\text { - IBRs are inherently uncertain and, therefore, } \\
\text { turbulent, confusing, and stressful } \\
\text { - Exclusivity is not guaranteed } \\
\text { - People in IBRs can have different wants, needs, and } \\
\text { expectations within the relationship, which may change } \\
\text { for the duration of the relationship } \\
\text { - IBRs elicit negative affect (jealousy, hurt) }\end{array}$ \\
\hline
\end{tabular}

Sub-themes 1 and 2: Increased amounts of self-disclosure lead to increased intimacy.

Other interactions can also lead to increased intimacy. People in an "in between" relationship

experience increases in self-disclosure, as well as other interactions, such as shared activities.

When this occurs, intimacy also increases. According to Amy (F, 20), "It was from barely any

interaction at all. After [initiating a] conversation, sobrang nag-peak 'yong interaction namin 
(our interaction really peaked)." Ellie (F, 21) said that her "in between" relationship "started out very casual," then she "started watching [her partner's] games, and he would watch [her] shows." They would spend weekends together in that her partner "would come over" and she “would [also] come over." Dan (M, 24) said, "What [really changed] was the time ... we spent together. From before [na] twice a week, naging, at the minimum, four times a week. Minsan, twice a day (it became, at the minimum, four times a week. Sometimes, twice a day)," whereas Connor (M, 21) narrated that he and his partner would be together every day, until "parang nagiging intimate na lang yung pagsasama niyo (it was as if [their] relationship was becoming intimate)."

\section{Theme 2: Expectancy changes and violations as well as turning points can occur within}

IBRs. Sub-themes 3 and 4: People's expectancies can either be changed or be violated within the relationship. Turning points, which signal change, can occur as well. Ellie (F, 21) expected "more time for just the two of [them], rather than be with a group of friends, and more time outside of school instead of just hanging out during the breaks." It was even expected from Dan (M, 24) that "kailangan may gawin kami (he and his partner had to do something)," if they had nothing to do on Friday nights. Amy (F, 20) was conscious of not violating any expectancies, saying: "Kahit na sabihin ko lang sa kanya na, 'I really like you, I really like these things about you,' feeling ko madadali siya lalo. Like, it would make her expect more out of me. (Even if I were to only tell [my partner] that, 'I really like you, I really like these things about you," I feel that she would rush into things even more. Like, it would make her expect more out of me.)" Bill $(\mathrm{M}, 22)$ was so sure of his partner's stand on their relationship, so when he "asked him to be [his boyfriend] and he said no because he wasn't ready yet," it confused Bill a lot. Considering that expectancy changes and violations can also mark changes within the relationship, they can also 
be considered as turning points. Both Amy and Bill's situations illustrate how these periods of change within their "in between" relationships make them all the more volatile.

Theme 3: IBRs are characterized by relational uncertainty. The four types of relational uncertainty — definitional uncertainty, behavioral norm uncertainty, mutuality uncertainty, and future uncertainty — are prevalent in emerging adults" "in between" relationships.

Sub-theme 5: People, regardless what their initial relationship is, start to become unsure of the state of the relationship. Connor (M, 21) puts it succinctly: "Iniisip ko, 'Kami ba o hindi? Sasabihin ko ba sa [mga] kaibigan ko na kami ba o hindi?' Mga ganun. ... 'Di ko na lang pinapansin yung uncertainty. Siyempre, mapapaisip ka, pero ako, iniisip ko na lang na kung sa'n ka masaya. Kung dito ka masaya sa kung saan malabo tayo, sige, malabo na lang tayo. ... 'Pag may nagtatanong na 'tayo ba?, ' sinasagot ko 'secret' or 'ewan' (I think, 'Are we together or not? Am I going to tell my [friends] that we're together or not?' Something like that. ... I don't pay attention to the uncertainty. Of course, you'd wonder, but I thought of where [my partner] was happy. If she's happy with this, that we're unclear, okay, then we're unclear. ... If someone asks if we're together, I answer with 'secret' or 'I don't know').” Dan (M, 24) echoes Connor's sentiments: "When friends would ask us seriously, we didn't know what to answer, or we'd answer [that] we're friends." Ellie (F, 21) was asking herself, "What are we?" She "was confused," and she "wasn't sure what they were. "We're not just friends; we're something more, [but] we weren't exactly labeled as 'boyfriend and girlfriend."”

Sub-theme 6: They also become unsure of how to behave within the relationship, of whether their feelings are reciprocated or not, of their or their partner's commitment to the relationship and where the relationship could lead. Bill $(\mathrm{M}, 22)$ thought that he "screwed up" 
asking his partner to be his boyfriend, and that he misread his partner. He then became confused and "really awkward" in terms of their relationship. Connor (M, 21) also said, " Di ko talaga alam kung sa'n ako pupuwesto. 'Yon talaga 'yong medyo nahirapan ako. ... Nakakakuha na'ko $n g$ hint, pero siyempre ayokong i-assume na may gusto siya sa akin (I really don't know where to place myself. That's where I sort of had a hard time. ... I was getting hints, but of course I didn't want to assume that she liked me)." Dan (M, 24) and his partner "talked about [their relationship] in the sense na parang joke na tayo, pero hindi (that it was like they were jokingly together, but they were not)."

Sub-theme 7: Reducing this uncertainty could lead to either the IBR's development into a romantic relationship or to its termination. Ellie's (F, 21) relationship ended when her partner disclosed that he was, in fact, in a committed relationship. When Amy's (F, 20) partner realized that "hindi pala same 'yong expectations namin (their expectations were not actually the same)," their relationship subsequently "came to an end."

Theme 4: Topic avoidance occurs within and maintains IBRs. Relationship issues, such as the state of the relationship, are one of the topics that emerging adults in "in between relationships" avoid. They do so in order to protect their relationship, and because there is uncertainty in terms of their partner's feelings as well as their expectations from the "in between" relationship.

Sub-themes 8, 9, and 10: People in IBRs avoid talking about the state of the relationship. Talking about the state of the relationship could lead to its termination. People would rather choose to "play it safe" than "rock the boat." Amy (F, 20) "was scared of what [talking about the state of the relationship] might have led to," so she also avoided talking about their feelings “kasi unang-una, parang may suspetsiya na ako na she expected something different (because 
first of all, [she] already had a suspicion that [her partner] expected something different)" ... [she] knew it would disappoint [her partner]," whereas Ellie was "afraid of speaking out and then making things go bad." She "wasn't sure [of] how [her partner] would react;" she "didn't want to jinx it." Bill $(\mathrm{M}, 22)$ did not talk about it either, saying: "it was a thing. I didn't wanna be pushy, I didn't wanna like, I don't know... cross some line na that would ruin everything," and Dan's $(\mathrm{M}, 24)$ friends assumed that he and his partner were already official, but "[they'd] never talk about it at all." He "didn't bring it up," so he "just waited for [his partner] to bring it up or just kept quiet."

\section{Theme 5: Cognitions, affect, and behavior (CABs) associated with IBRs include} CABs associated with friendships and romantic relationships. There is an overlap between the cognitions, affect, and behavior linked with friends and the cognitions, affect, and behavior associated with romantic partners. This overlap causes the uncertainty that is common in emerging adults" "in between" relationships; and uncertainty may cause the cognitions, affect, and behavior to overlap as well.

Sub-themes 11 and 12: People in IBRs think, feel, and do things that they associate with friendships. They also think, feel, and do things that they associate with romantic relationships. Connor (M, 21) was "[in sync]" with his partner, and felt that he was her male best friend, but he also thought, "Shit, eh 'di every [Valentine's Day], every birthday niya, every event, dapat may ibigay ako? May gawin ako? (Shit, so every Valentine's Day, every time it's her birthday, every event, I have to give something? To do something?)" Amy (F, 20) described her conversations with her partner as "the kind of conversation that she would associate with somebody that she was more than friends with," and contrasted them with her conversations with her best friend: "I would [also] talk to [my best friend] all the time, pero hindi naman 'yong tipong I have to know 
everything that she's doing. It's not like I'm interested in asking [my best friend], '[Nasa'n] ka ngayon?' (... but it wasn't as if I have to know everything she's doing. It's not like I'm interested in asking my best friend, 'Where are you now?')"

Theme 6: IBRs have advantages. Emerging adults maintain the status quo of "in between" relationships because of the positive consequences it allows, such as a sense of safety and companionship, as well as sex and positive feelings.

Sub-themes 13, 14, and 15: IBRs elicit positive affect. IBRs provide people with companionship and sex without the commitment associated with a romantic relationship. IBRs also provide perceived safety. Ellie (F, 21) was "happy and excited" at first, thinking that her "in between" relationship "was good," because "it's been a while ... since [she] had a relationship, so it was nice [for her] to have that [companionship] again." Bill's $(\mathrm{M}, 22)$ "in between" relationship was his first "guy, first 'relationship'," so it made him feel "kilig” (giddy) and even “flustered," whereas Dan's (M, 24) “felt like [their] own thing ... it felt special ... mas [elevated] (more elevated)," because he and his partner "kept it quiet." Connor (M, 21) was also happy, saying that there was no boring moment throughout the relationship. He liked that "may tao na parang, kaya kong [kausapin] and nagre-reciprocate $n g$ care and pagmamahal (there was someone that he could talk to that reciprocates his care and love)."

Sub-theme 16: In retrospect, IBRs can become a learning experience. Amy (F, 20) noticed that she was "really careful about [herself]," in that she experienced an "in between" relationship and came out "unscathed," but it taught her a lot about herself and made her recognize that she "wanted to avoid commitment so badly." Ellie's views on relationships changed: "If you are in a relationship, it shouldn't be uncertain. You should both be [on] the same page." Dan $(M, 24)$ learned that he had to be "more verbal about my feelings and thoughts 
about [his "in between" relationship]," and that he would be more expressive about them in his eventual relationships. Connor $(\mathrm{M}, 21)$ thought that he was too immature to be in a relationship at that time, saying: "kailangan ko pang ayusin ['yong] sarili ko [before I enter another relationship] (I need to fix myself...).”

Theme 7: IBRs also have disadvantages. "In between" relationships are turbulent and stressful because of their inherent lack of certainty and clarity. These, compounded with implied exclusivity, erratic and sometimes, unilateral expectations, and negative feelings, contribute to the tension characteristic of "in between" relationships.

Sub-theme 17: IBRs are inherently uncertain and, therefore, turbulent, confusing, and stressful. Dan (M, 24) plainly sums up his experience in an "in between" relationship: "In the long run, hindi ko nagustuhan yung ambiguity of it all. Kasi may times na nag-aaway kami, pero it's not like may point yung away kasi hindi naman kayo 'boyfriend and girlfriend,' pero you share [a] closeness, so in a way, you get why you fight, but then, naaasar ka: 'Bakit kayo nagaaway [when] you're just supposed to be friends?' It became complicated (In the long run, I didn't like the ambiguity of it all. Because there are times when [my partner and I] fight, but it's not like there's a point to fighting because you aren't 'boyfriend and girlfriend,' but you share a closeness, so in a way, you get why you fight, but then, you get annoyed: 'Why are you fighting when you're just supposed to be friends?'...)."

Sub-theme 18: Exclusivity is not guaranteed. Bill $(\mathrm{M}, 22)$ found out that his partner was in love with someone else, and Ellie (F, 21) also discovered that her partner "had a girlfriend, and he was [kind of] seeing [Ellie] on the side." They broke up with their partners subsequently.

Sub-theme 19: People in IBRs can have different wants, needs, and expectations within the relationship, which may change for the duration of the relationship. Amy (F, 20) began her 
"in between" relationship thinking that she wanted to take it to the next level, but "when it was actually happening, [she realized that] she didn't want it to be any more than [what it was]." She continues, "noong patagal na nang patagal, it became more apparent na magka-iba na kami ng gusto (the longer we were in the relationship, it became more apparent that we wanted different things out of it) ... I wanted to avoid commitment so badly.”

Sub-theme 20: IBRs elicit negative affect. Dan (M, 24) felt that his fights with his partner had no point and were invalid, because they were not "boyfriend and girlfriend" anyway. Connor's (M, 21) relationship problems "revolved" around its lack of clarity: "Ano ba talaga kami? Lahat ng problema laging bumabalik doon (What are we, really? All of [our] problems would always go back to that)."

\section{General Discussion}

"In between" relationships, similar to any interpersonal relationship, develop through give-and-take interactions. These sets of interactions are mainly dependent on the relationship that people have (e.g., people who consider themselves friends are expected to behave differently from romantic partners, and vice-versa). Eventually, however, people may start thinking, feeling, and doing things that they associate with romantic relationships with their partner. Their relationship dynamic shifts from "strictly platonic" to "in between strictly platonic and strictly romantic," the relationship already including romantic elements. This may occur regardless of the pre-existing state of their relationship, i.e., whether they labeled themselves acquaintances, friends, or "friends with benefits." The overlap of the cognitions, affect, and behavior (CABs) linked with the pre-existing state of their relationships and the CABs associated with romantic relationships, as well as the change in relationship dynamic violate expectancies and create a new set of interactions - all of which, therefore, cause uncertainty. This uncertainty characterizes 
their relationship, eventually leading to the beginning of an "in between" relationship, provided that this uncertainty is not reduced.

Generally, the advantages of "in between" relationships, such as intimacy, companionship, and perceived safety, are more prominent during the initial stages of the relationship, and these motivate emerging adults to maintain it. The disadvantages, such as confusion, varying expectations, and negative feelings, would later outweigh whatever the initially perceived positive consequences are. The uncertainty (whether definitional or the other types), as well as the topic avoidance that both characterize "in between" relationships are not only maintenance strategies, but also sources of turbulence and stress that more often than not factor into its termination.

Despite such, the underlying reasons emerging adults choose to stay in an "in between" relationship, while avoiding opening up certain "risky" topics, such as the state of the relationship, vary from not wanting to commit to not wanting to ruin the arrangement. Regardless of the inherent uncertainty of an "in between" relationship as well as the resulting stress from it, emerging adults would choose maintaining the status quo of the relationshiptherefore, avoiding potentially relationship-terminating conversations_over not being in it at all. The perceived risk associated with openly communicating with their partner reinforces both the uncertainty and topic avoidance that are prevalent in "in between" relationships.

These conditions increase the possibility of the relationship terminating, validating Berger and Roloff's (1982) suggestion that because increased uncertainty, or the absence or lack of uncertainty reduction, demands more time and energy in order to achieve understanding, increased demands of time and energy can be draining. Parks and Adelman (1983) also noted that "the overall amount of communication with the romantic partner was the strongest predictor 
of breakups" and established that uncertainty was positively linked to breakups. This could be why a good number (12 out of 21 , or $57 \%$ ) of this study's “in between" relationships have been terminated and did not transition into a romantic relationship.

There is, however, another factor that needs to be considered about "in between" relationships and why they end, which is the partners' motivations for and expectations from the relationship. People engage in an "in between" relationship for numerous reasons, and they can have different wants, needs, and expectations from and within the relationship — all of which may or may not correspond with their partner's. Reducing uncertainty (by either directly communicating with their partner, or using the secret tests identified by Baxter and Wilmot (1985), such as joking to your friend about being a couple or flirting with someone else to see their reaction) can reveal these differences in motivations and expectations, which can also make the relationship's termination more likely to happen. These could also explain unsuccessful attempts to escalate the "in between" relationship.

The researchers propose three types of "in between" relationships based on their status: maintained, terminated-escalated, and terminated-reverted. The maintained type of "in between" relationships is ongoing, whereas both the terminated-escalated and terminated-reverted types have been ended. Terminated-escalated "in between" relationships have transitioned into romantic relationships. However, the terminated-reverted types have transitioned back into what their relationship was prior to it being an "in between" relationship (e.g., friends that became "in between" partners and then became friends again) or have de-escalated it, but not necessarily to what the previous state of their relationship was (e.g., "friends with benefits" that became "in between" partners and then became "just friends"). 
The researchers also suggest two types of "in between" relationships based on the partners' desires and goals for the relationship: aligned and misaligned. The aligned type of "in between" relationships is wherein one partner's desires and goals correspond with the other's. There are three sub-types of aligned "in between" relationships: aligned-escalate, alignedmaintain, and aligned-revert. These sub-types reflect the aforementioned correspondence between partners and even predict the likely outcome of the "in between" relationship. For example, an aligned-maintain "in between" relationship, wherein both partners want to keep the relationship as is, is more likely to be kept the same way. The misaligned type of "in between" relationships, however, is wherein there is no correspondence of desires and goals between partners. There are three scenarios that illustrate misaligned "in between" relationships: 1) one partner wants to escalate the "in between" relationship or transition it to a romantic relationship, but the other partner wants to maintain the relationship or keep it as is; 2) one partner wants to escalate it, but the other partner wants to revert it or transition it to what their prior relationship was; and 3) one partner wants to maintain it, but the other partner wants to revert it. The likely outcome of a misaligned "in between" relationship is to eventually become a terminated-reverted "in between" relationship.

\begin{tabular}{|c|c|c|c|c|}
\hline & & & Partner 1 & \\
\hline & & Escalate & Maintain & Revert \\
\hline \multirow{3}{*}{ Partner 2} & Escalate & Aligned-Escalate & Misaligned & Misaligned \\
\hline & Maintain & Misaligned & Aligned-Maintain & Misaligned \\
\hline & Revert & Misaligned & Misaligned & Aligned-Revert \\
\hline
\end{tabular}

Based on the proposed types of "in between" relationships, 6 were maintained, 3 were terminated-escalated, and 12 were terminated-reverted. Two of the maintained "in between" relationships became terminated-escalated weeks after the interviews were conducted. However, 
the researchers cannot fully determine how many aligned and misaligned "in between" relationships there were, because no two-party interviews were conducted.

\section{Conceptual Framework}

The researchers conceptualized a framework that illustrates the development of "in between" relationships. This framework incorporates concepts from Altman and Taylor's (1973) social penetration theory, Knapp's (1984) relational stages model, Baxter and Bullis' (1986) turning point approach, Berger and Calabrese's (1975) uncertainty reduction theory, as well as Burgoon's (1978) expectancy violations theory.

The transition from acquaintances, friends, or "friends with benefits" (from this point, referred to as "pre-existing relationship") to romantic partners involves mutual self-disclosure, positive expectancy violations, turning points, and decreased uncertainty. Figure 1 depicts this transition. According to social penetration theory, relationships progress through self-disclosure. It is through this, as well as other socially penetrative behaviors (such as shared activities), that intimacy in a relationship increases. Expectancy violations (specifically positive expectancy violations) and turning points also occur within the transition. They both mark change in the relationship and may result to increased or decreased uncertainty. Because relationships develop by means of lessening uncertainty, decreased uncertainty makes it more likely for a relationship to become a romantic relationship, regardless of its pre-existing label, i.e., acquaintances, friends, or "friends with benefits." 


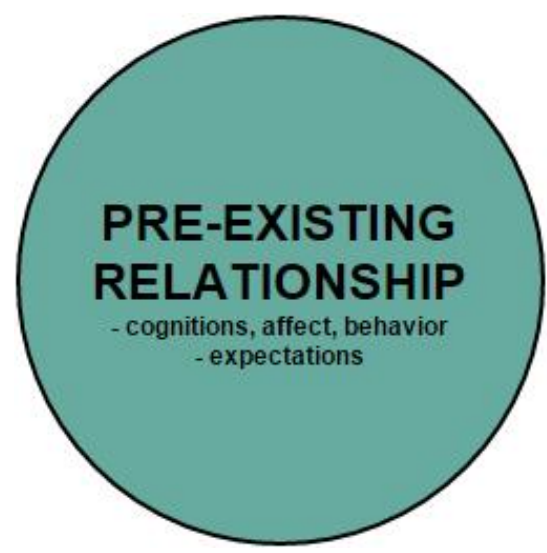

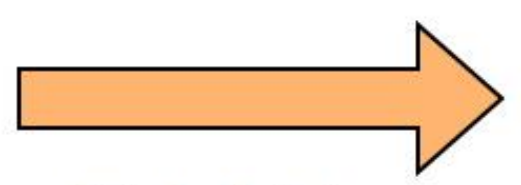

Mutual self-disclosure, positive expectancy violations, turning points, decreased uncertainty

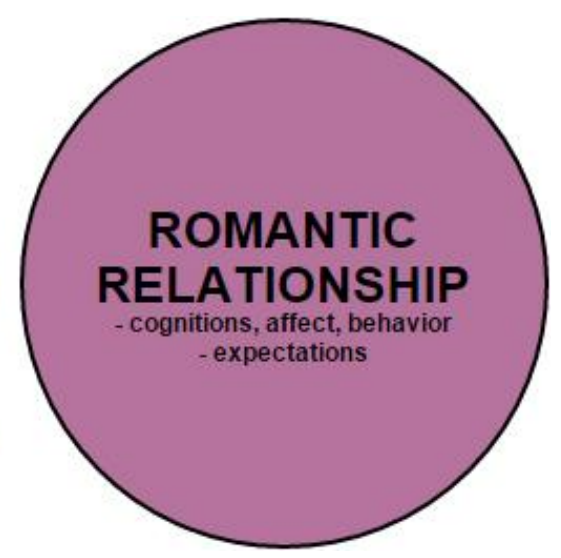

Figure 1. Transition from pre-existing relationship to romantic relationship

Relationships are linked to specific cognitions, affect, and behavior (CABs) and expectations - the set of which varies between acquaintances, friends, "friends with benefits," romantic partners, etc. Nevertheless, the CABs and expectations associated with the pre-existing relationship overlap with the CABs and expectations linked to romantic relationships. This overlap causes uncertainty. Figure 2 depicts this overlap. Because of this overlap and the increased uncertainty, a transitional relationship emerges and is initiated - the "in between" relationship.

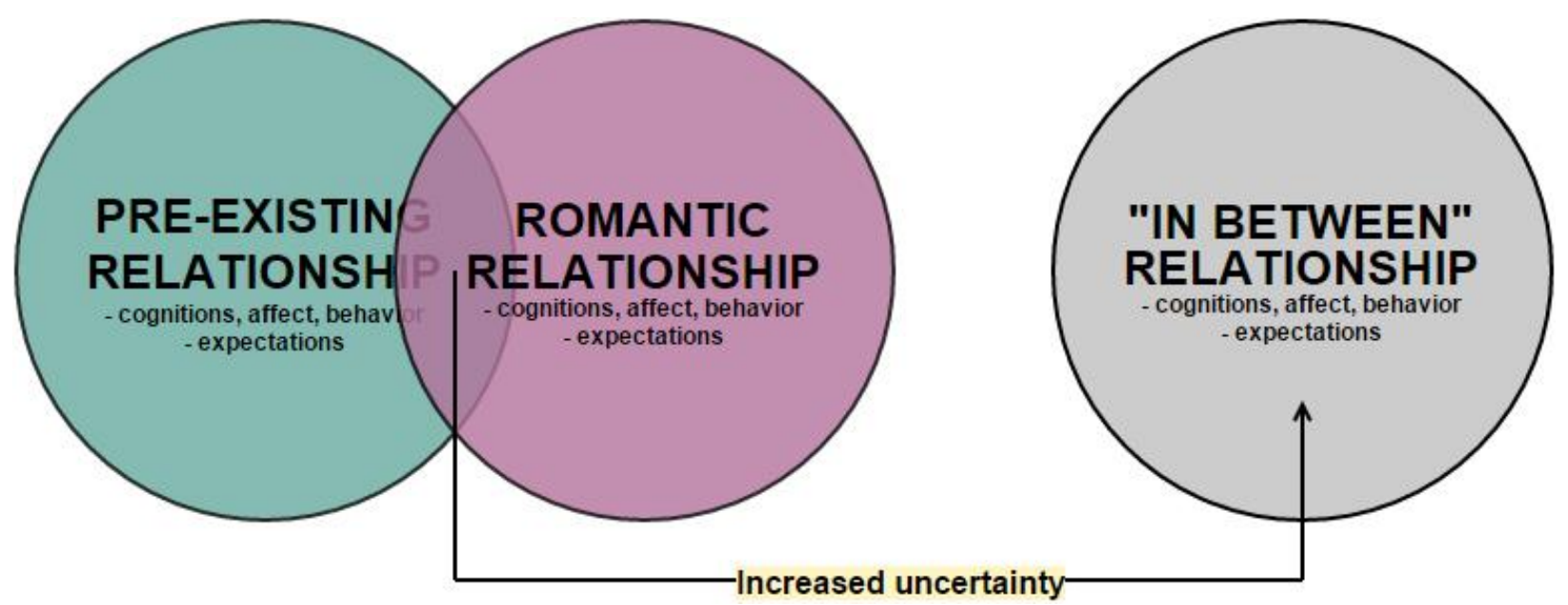

Figure 2. Overlap of cognitions, affect, and behavior (CABs) and expectations, and initiation of "in between" relationships 
The researchers, then, illustrate the development of "in between" relationships by combining Figures 1 and 2. Decreased uncertainty allows for the transition of a relationship to a romantic relationship, whereas increased uncertainty allows for its transition to an "in between" relationship. Figure 3 depicts the development of "in between" relationships. Topic avoidance maintains "in between" relationships, and partners' expectations (and whether they align or otherwise) are usually unknown at this point of the relationship. However, decreased uncertainty and aligned-maintain expectations (as in, the aligned-maintain "in between" relationship) allow for the relationship's maintenance.

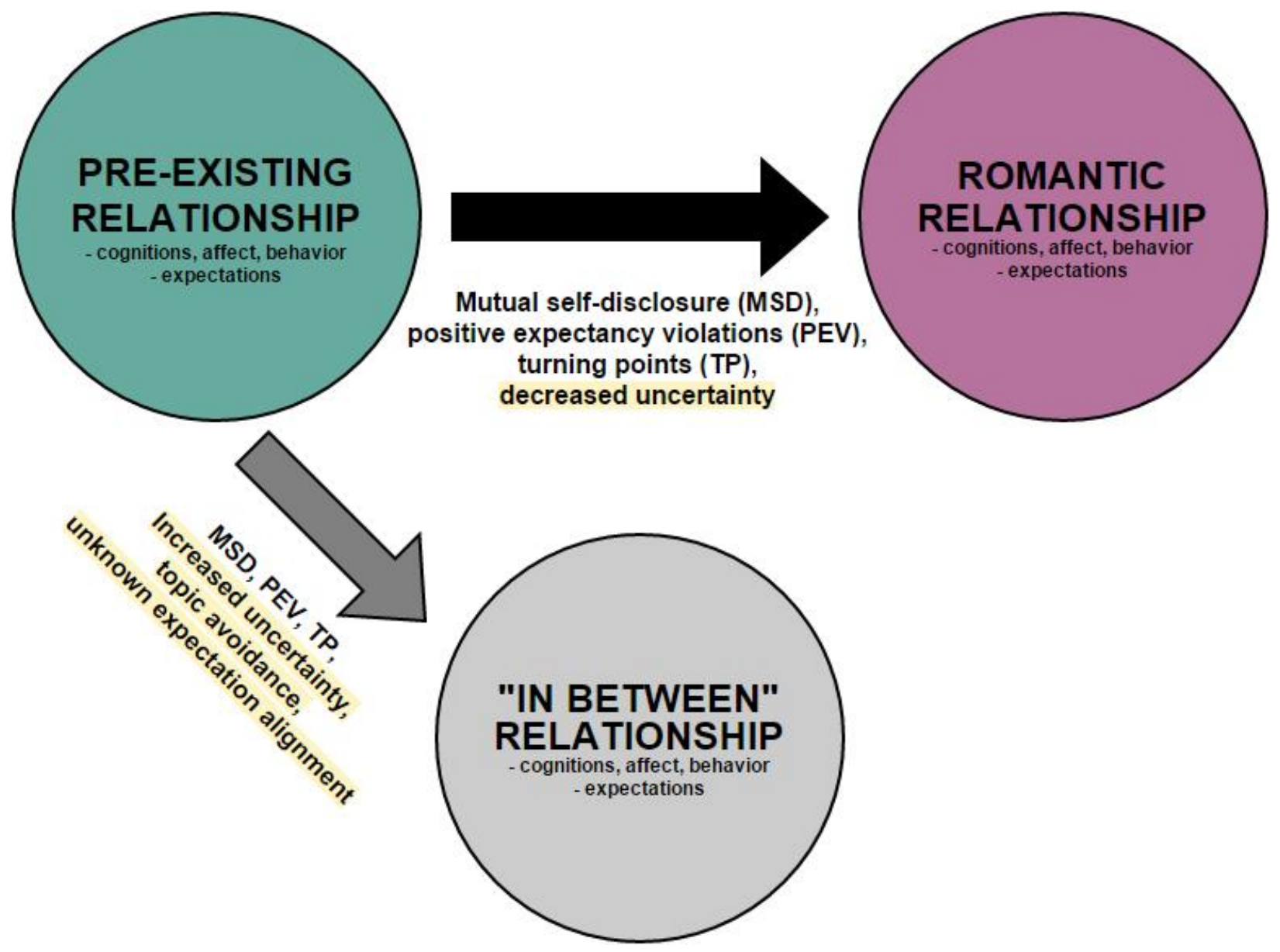

Figure 3. Development and maintenance of "in between" relationships 
The termination of an "in between" relationship can occur in two ways: 1) the relationship can escalate into a romantic relationship (as in, the terminated-escalated "in between" relationship); or 2) the relationship can revert into its previous state, or de-escalate (as in, the terminated-reverted "in between" relationship). Figure 4 depicts the termination of "in between" relationships. Decreased uncertainty and aligned-escalate expectations (as in, the aligned-escalate "in between" relationship) allow for its escalation, whereas decreased uncertainty and aligned-revert or misaligned expectations (as in, the aligned-revert "in between" relationships or the misaligned "in between" relationship) allow for its reversion.

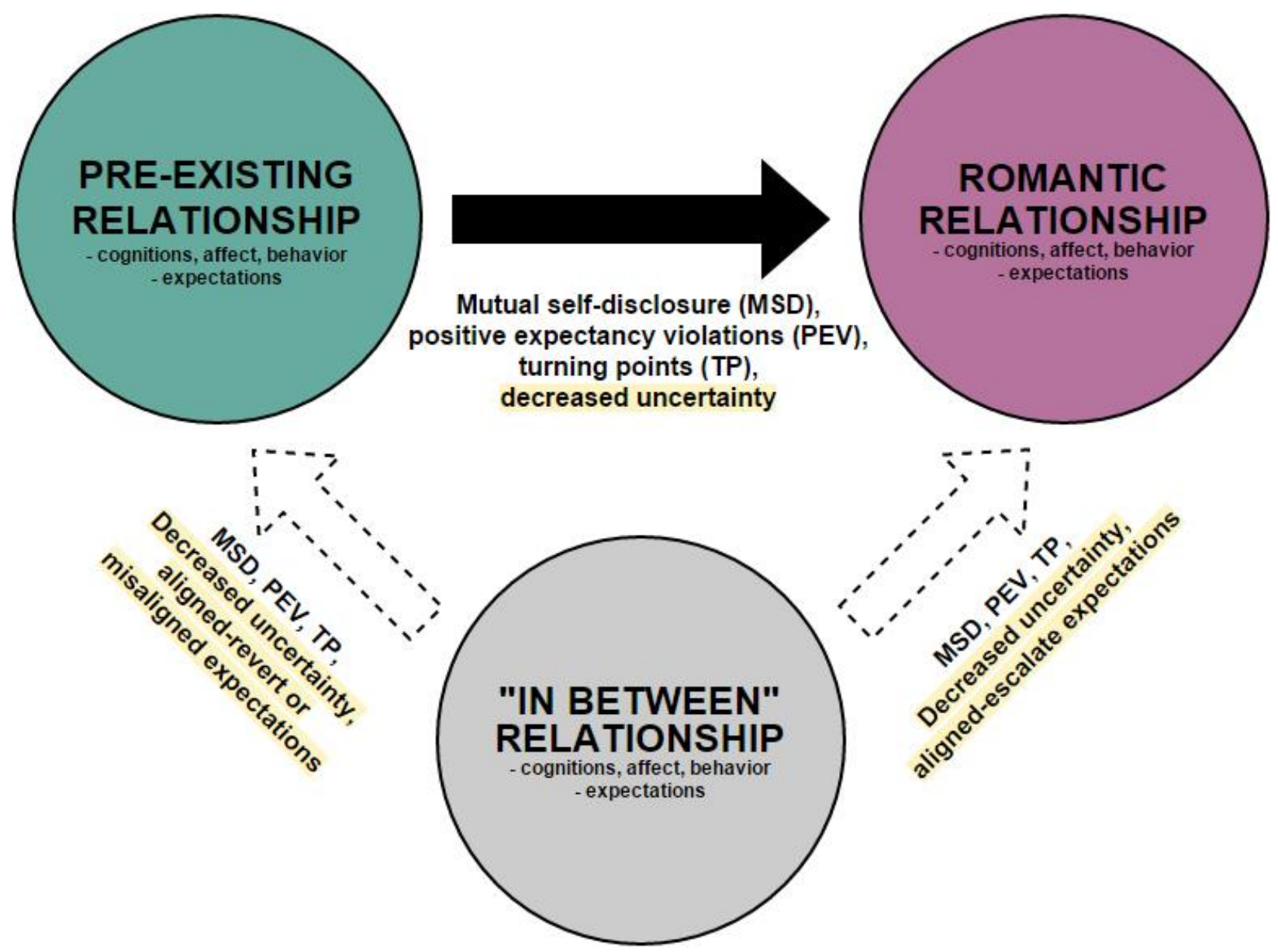

Figure 4. Termination of "in between" relationships 


\section{CHAPTER FIVE}

\section{Summary, Conclusion, and Recommendations}

\section{Summary}

The objective of this study was to provide insight on the nature of emerging adults' "in between" relationships, in terms of relationship development (initiation, maintenance, and termination), as well as the motivations behind these relationships. The researchers identified seven themes and 20 sub-themes that describe the nature and motivations behind "in between" relationships. They also conceptualized a framework that illustrates the development of "in between" relationships, incorporating Altman and Taylor's (1973) social penetration theory, Knapp's (1984) relational stages model, Baxter and Bullis' (1986) turning point approach, Berger and Calabrese's (1975) uncertainty reduction theory, as well as Burgoon's (1978) expectancy violations theory. The researchers proposed three types of "in between" relationships based on their status (maintained, terminated-escalated, and terminated-reverted), as well as two other types based on the partners' expectations for the relationship (aligned and misaligned).

Uncertainty is present in all "in between" relationships, but the types of uncertainty are not consistent in every "in between" relationship, except for definitional uncertainty. Since these relationships are not clear or well-defined, people cannot tell which behaviors are acceptable within the bounds of the relationship and otherwise. Decreasing this uncertainty and finding out that both partners' desires and goals for the relationship are aligned allow for escalation, maintenance, and reversion, depending on which outcome both partners want. However, increased uncertainty and misaligned expectations make relationship termination and reversion even more likely to happen. 


\section{Conclusion}

"In between" relationships are, in essence, transitional relationships as well as legitimate, valid relationships in themselves, despite the lack of a word that defines it amongst partners and the resulting uncertainty. These relationships seem casual and enjoyable, but similar to romantic relationships, "in between" relationships can pose real emotional risks and should not be taken lightly. Ideally, there should be constant, clear communication amongst "in between" partners regarding their desires and goals for the relationship as to avoid misaligned expectations, stress, and possible heartbreak.

The phenomenon of "in between" relationships also demonstrates the fluidity of interpersonal relations, giving a new perspective on how to look at platonic and romantic relationships. The line separating friendships and romantic relationships used to be well-defined. The rise of this phenomenon shows us that relationships are not a black-or-white or all-ornothing binary wherein two people are either "just friends" or romantic partners. Relationships have become more complex, and "in between" relationships are manifestations of how both culture and people's wants and needs from a relationship have evolved interdependently.

\section{Recommendations}

The researchers propose that future studies on "in between" relationships can and should be done, keeping the following recommendations in mind. First, they should have a larger and more proportional sample, i.e., a more-or-less equal number of maintained, terminated-escalated, and terminated-reverted "in between" relationships. Second, their participants should be two parties of an "in between" relationship, as no two-party interviews were conducted in this study. Third, they should be expanded to account for other age groups, such as adolescents (13 to 18 
years old) and young adults (18 to 40 years old). Lastly, the researchers also suggest that future studies should be longitudinal, documentation starting at the initiation (or at least, at the maintenance) of the "in between" relationship.

The researchers also propose that future studies should look into other factors that could influence one's being in an "in between" relationship, such as attachment styles. 


\section{Bibliography}

Abad-Santos, A. (2014, June 24). How dates got so complicated. Vox. Retrieved from http://www.vox.com/2014/6/24/5823972/how-dates-got-so-complicated

Afifi, W. A., \& Burgoon, J. K. (1998). "We never talk about that": A comparison of cross-sex friendships and dating relationships on uncertainty and topic avoidance. Personal Relationships, 5(3), 255-272.

Afifi, W. A., \& Guerrero, L. K. (1998). Some things are better left unsaid II: Topic avoidance in friendships. Communication Quarterly, 46(3), 231-249.

Afifi, W. A., \& Metts, S. (1998). Characteristics and consequences of expectation violations in close relationships. Journal of Social and Personal Relationships, 15(3), 365-392.

Altman, I., \& Taylor, D. A. (1973). Social penetration: The development of interpersonal relationships. Holt, Rinehart \& Winston.

Arnett, J. J. (2004). Emerging adulthood: The winding road from the late teens through the twenties. New York, NY: Oxford University Press.

Avtgis, T. A., West, D. V., \& Anderson, T. L. (1998). Relationship Stages: An Inductive Analysis identifying Cognitive, Affective, and Behavioral Dimensions of Knapp's Relational Stages Model. Communication Research Reports, 15(3): 280-287.

Baxter, L. A., \& Bullis, C. (1986). Turning points in developing romantic relationships. Human Communication Research, 12(4), 469-493.

Baxter, L. A., \& Wilmot, W. W. (1984). Secret tests. Human Communication Research, 11(2), $171-201$.

Baxter, L. A., \& Wilmot, W. W. (1985). Taboo topics in close relationships. Journal of Social and Personal Relationships, 2(3), 253-269. 
Berger, C. R. (1979). Beyond initial interaction: Uncertainty, understanding, and the development of interpersonal relationships. Language and social psychology, 122-144.

Berger, C. R., \& Bradac, J. J. (1982). Language and social knowledge: Uncertainty in interpersonal relations (Vol. 2). Hodder Education.

Berger, C. R., \& Calabrese, R. J. (1975). Some explorations in initial interaction and beyond: Toward a developmental theory of interpersonal communication. Human Communication Research, 1(2), 99-112.

Bisson, M. A., \& Levine, T. R. (2009). Negotiating a friends with benefits relationship. Archives of sexual behavior, 38(1), 66-73.

Burgoon, J. K. (1978). A communication model of personal space violations: Explication and an initial test. Human Communication Research, 4(2), 129-142.

Burgoon, J. K. (2015). Expectancy Violations Theory. The International Encyclopedia of Interpersonal Communication, 1-9.

Carroll, J. S., Willoughby, B., Badger, S., Nelson, L. J., Barry, C. M., \& Madsen, S. D. (2007). So close, yet so far away: The impact of varying marital horizons on emerging adulthood. Journal of Adolescent Research, 22(3), 219-247.

Claxton, S. E., \& van Dulmen, M. H. M. (2013). Casual Sexual Relationships and Experiences in Emerging Adulthood. Emerging Adulthood, 1(2), 138-150.

DTR. (n.d.). In Urban Dictionary. Retrieved from http://www.urbandictionary.com/define.php?term=DTR

Elejalde-Ruiz, A. (2014, January 21). Forever? Maybe. But not just yet. Chicago Tribune. Retrieved from http://articles.chicagotribune.com/2014-01-21/features/sc-fam-0121ambivalence-2-20140121_1_simon-schuster-divorce-couples 
Guerrero, L. K., \& Mongeau, P. A. (2008). On Becoming "More Than Friends" The Transition from Friendship to Romantic Relationship. In S. Sprecher, A. Wenzel, \& J. Harvey (Eds.), Handbook of Relationship Initiation (pp. 175-194). Abingdon: Taylor \& Francis.

Grello, C. M., Welsh, D. P., \& Harper, M. S. (2006). No strings attached: The nature of casual sex in college students. Journal of Sex Research, 43(3), 255-267.

Halpern, C.T., Waller, M.W., Spriggs, A., \& Hallfors, D.D. (2006). Adolescent predictors of emerging adult sexual patterns. Journal of Adolescent Health, 39(6), 926.e1-926.e10.

Jayson, S. (2014, January 21). Is it a date? Or hanging out? Survey reflects confusion. USA Today. Retrieved from http://www.usatoday.com/story/news/nation/2014/01/21/datehangout-relationships/4397601/

Johnson, A. J., Wittenberg, E., Haigh, M., Wigley, S., Becker, J., Brown, K., \& Craig, E. (2004). The process of relationship development and deterioration: Turning points in friendships that have terminated. Communication Quarterly, 52(1), 54-67.

Johnson, A. J., Wittenberg, E., Villagran, M. M., Mazur, M., \& Villagran, P. (2003). Relational progression as a dialectic: Examining turning points in communication among friends. Communication Monographs, 70(3), 230-249.

Knapp, M. L., \& Vangelisti, A. L. (2005). Relationship stages: A communication perspective. Interpersonal communication and human relationships, 36-49.

Knobloch, L. K., \& Carpenter-Theune, K. E. (2004). Topic avoidance in developing romantic relationships associations with intimacy and relational uncertainty. Communication Research, 31(2), 173-205.

Knobloch, L. K., \& Solomon, D. H. (1999). Measuring the sources and content of relational uncertainty. Communication Studies, 50(4), 261-278. 
Messman, S. J., Canary, D. J., \& Hause, K. S. (2000). Motives to remain platonic, equity, and the use of maintenance strategies in opposite-sex friendships. Journal of Social and Personal Relationships, 17(1), 67-94.

Mongeau, P. A., Knight, K., Williams, J., Eden, J., \& Shaw, C. (2013). Identifying and explicating variation among friends with benefits relationships. Journal of Sex Research, 50(1), 37-47.

Mongeau, P. A., Serewicz, M. C. M., Henningsen, M. L. M., \& Davis, K. L. (2006, February). Sex differences in the transition to a heterosexual romantic relationship. In Lawrence Erlbaum Associates.

Parks, M. R., \& Adelman, M. B. (1983). Communication networks and the development of romantic relationships: An expansion of uncertainty reduction theory. Human Communication Research, 10(1), 55-79.

Planalp, S., \& Honeycutt, J. M. (1985). Events that increase uncertainty in personal relationships. Human Communication Research, 11, 153-604.

Reeder, H. M. (2000). 'I like you... as a friend': The role of attraction in cross-sex friendship. Journal of Social and Personal Relationships, 17(3), 329-348.

Regan, P. C., \& Dreyer, C. S. (1999). Lust? Love? Status? Journal of Psychology \& Human Sexuality, 11(1), 1-24.

Solomon, D. H., \& Knobloch, L. K. (2001). Relationship uncertainty, partner interference, and intimacy within dating relationships. Journal of Social and Personal Relationships, 18(6), 804-820. 
Stanley, S. M. (2002, June). What is it with men and commitment anyway? Paper presented at the Smart Marriages Conference, Washington, DC. Retrieved from http://prepinc.com/main/docs/commitment.pdf

Stanley, S. M. (2014, June 26). Is This a Date? Psychology Today. Retrieved from https://www.psychologytoday.com/blog/sliding-vs-deciding/201406/is-date

Sternberg, R. J. (1986). A triangular theory of love. Psychological Review,93(2), 119-135.

Taylor, D. A. (1968). The development of interpersonal relationships: Social penetration processes. The Journal of Social Psychology, 75(1), 79-90.

Wentland, J. J., \& Reissing, E. (2014). Casual sexual relationships: Identifying definitions for one night stands, booty calls, fuck buddies, and friends with benefits. The Canadian Journal of Human Sexuality, 23(3), 167-177.

Williams, L. R., \& Adams, H. L. (2013). Friends with benefits or "friends" with deficits? The meaning and contexts of uncommitted sexual relationships among Mexican American and European American adolescents. Children and Youth Services Review, 35(7), 11101117. 


\section{APPENDIX A}

\section{Informed Consent Form}

Good day! We are Psychology 199 (Research in Psychology) students from Kalayaan College, and we are conducting interviews for our thesis on emerging adults' "in between" relationships.

The interview is composed of several questions that will require you to give information about yourself, your current/previous "in between" relationship, and your partner/ex.

For the purpose of this study, an "in between" relationship is an experience/relationship between friendships and romantic relationships wherein you are unsure of the state of the relationship, or what the relationship actually is.

This interview is approximately 60-minutes long and will be recorded.

We assure you that your identity will remain confidential and that your answers, if published, will not be connected to your identity. All audio and written records will also be confidential. You may ask us a copy of the questions before deciding whether or not to proceed with the interview, and if you wish to withdraw your participation from the study, you may also do so anytime without consequences.

Sincerely,

\section{Jamie Doble}

09773232134

cpm.doble@gmail.com

\section{Ein Gutierrez}

09493689732

reiniero.gutierrez@gmail.com 
I, the undersigned, agree to participate in this study entitled "What are we? The nature of, motivations behind emerging adults" "in between" relationships" with the full understanding of this study, its objectives, and its possible consequences. I also understand that the researchers may contact me for clarifications or follow-up questions after the interview through my contact details below.

Full Name:

Contact No.:

E-mail:

Signature:

Date: 


\section{APPENDIX B}

\section{$\underline{\text { Interview Questions }}$}

1. When did the "in between" relationship (IBR) start?

2. Describe your relationship before the IBR.

3. Tell us how your IBR started.

4. When did you realize you were no longer "just friends"?

- What made you realize this?

- What was your reaction when you realized this?

- What did you think during this time?

- Did you let your partner know what you thought?

- $\quad$ If yes, why, how, and how did they react?

- If no, would you let your partner know what you thought?

- $\quad$ If yes, why? How would you let them know what you thought?

- $\quad$ If no, why not?

- What did you feel during this time?

- $\quad$ Did you let your partner know what you felt?

- If yes, why, how, and how did they react?

- If no, would you let your partner know what you felt?

- $\quad$ If yes, why? How would you let them know what you felt?

- $\quad$ If no, why not?

- What did you do during this time?

- Why?

- $\quad$ How did your partner react? 
- Did you know what your partner thought/felt?

- $\quad$ If yes, how?

- $\quad$ If no, would you want to know what they thought/felt?

- $\quad$ If yes, why?

- $\quad$ If no, why not?

5. Describe your relationship during the IBR. (maintenance)

- Was it the same as before? If yes, how so? Which aspects were the same?

- Was it different than before? If yes, how so? Which aspects were different?

- What activities did you do together during the IBR? Which would you say were "just friends" activities? Which would you say were "couple" activities?

- What else did you think throughout the relationship? What else did you feel...? What else did you do...?

- Were there topics that you would not talk about? If yes, what were they? Why would you not talk about them?

6. How did you think/feel about the arrangement?

- $\quad$ Did you experience uncertainty? If yes, what kind/s of uncertainty did you experience? How do you feel about the uncertainty? How did you deal with the uncertainty?

- $\quad$ Did you want to maintain the status quo?

- $\quad$ If yes, why did you want to maintain the status quo? What comes with maintaining it?

- $\quad$ If no, why didn't you want to maintain the status quo? What comes with not maintaining it? 
- Would you rather maintain it or not maintain it? Why or why not?

- What did you like about the arrangement?

- What did you dislike about the arrangement?

- Would you change anything about the arrangement?

- $\quad$ Did the arrangement change how you think/feel about yourself? Relationships?

Love? Sex?

- Would you be in an IBR again?

7. Tell us how the IBR ended.

8. Describe your relationship after the IBR.

9. When did the IBR end?

- What do you think made the relationship last this long? 